\title{
UNVEILING PICOEUKARYOTIC DIVERSITY AND DISTRIBUTION IN THE BAY OF LARGE RESERVOIR SYSTEM
}

\author{
LI, Y. T. $.^{1,2^{*}}-$ LIU, K. S. ${ }^{*}-$ HoU, Y. Y. ${ }^{1}-$ YU, J. J. ${ }^{1}-$ DUAN, Y. H. ${ }^{1}-$ LIU, X. X. ${ }^{1}-$ HoU, J. J. ${ }^{1 * *}-$ \\ BI, Y. H. ${ }^{3 * *}$ \\ ${ }^{1}$ Hubei Key Laboratory of Edible Wild Plants Conservation and Utilization, Hubei Normal \\ University, Cihu Road, Huangshigang District, Huangshi, Hubei Province, 435002 China \\ ${ }^{2}$ Bengbu University, Bengbu 233030, China \\ ${ }^{3}$ State Key Laboratory of Freshwater Ecology and Biotechnology, Institute of Hydrobiology, \\ The Chinese Academy of Sciences, Wuhan 430072, China \\ *The first two authors made equal contributions to this paper. \\ **Corresponding authors (contributed equally) \\ J.J.Hou-e-mail: hjj6681@163.com, phone: +86-714-651-1613 \\ Y.H.Bi-e-mail: biyh@ihb.ac.cn, phone: +86-276-878-0016 \\ (Received $1^{\text {st }}$ Aug 2018; accepted $5^{\text {th }}$ Oct 2018)
}

\begin{abstract}
Few studies have reported about the diversity and distribution of picoeukaryotes in the ecosystem of reservoir bay. In this study, Sanger-based clone libraries of 18S rRNA gene were used to determine the picoeukaryotic diversity of three sampling sites; these sites were located across the Xiangxi Bay of Three Gorges Reservoir, China. The sampling sites were monitored across all four seasons in 2013. We identified 13 phyla in Xiangxi Bay. In this experimental survey, we found that picoeukaryotic community was dominated by three main phyla, namely, Cryptophyta, Chlorophyta, and Ciliophora (69.9\% of clones in all). Moreover, the remaining 10 phyla showed a relative abundance of less than $6 \%$. In Xiangxi Bay, the seasonal variability of communities overwhelms spatial patterns; upper reaches exhibited highest species diversity, whereas middle reaches exhibited lowest species diversity. The community temporal stability had decreased from upstream to downstream. Primary producers were dominant in all the sample sites, irrespective of the season. In Xiangxi Bay upstream, terrestrial microbes may be integral components of the microbial community assembly. In Xiangxi Bay, the distribution pattern of picoeukaryotes might have been affected by the mainstream of Three Gorges Reservoir.
\end{abstract}

Keywords: picoeukaryotes, microbial diversity, $18 \mathrm{~S}$ rDNA, tributary bay, distribution pattern

\section{Introduction}

Picoeukaryotes are widely distributed in aquatic environments, contributing significantly to biomass and primary production (Li, 1994; Caron et al., 2012). They are core members of aquatic microbial food webs and play a fundamental role in biogeochemical cycling (Massana et al., 2011). This indicates that they play an important role in maintaining the balance of water ecosystems (Biegala et al., 2003; Vaulot et al., 2008). Many studies have reported about the unexpected diversity of picoeukaryotes in Open Ocean, coastal areas, and estuaries (Massana et al., 2011; Wu et al., 2014; Farnelid et al., 2016).

Some studies have determined the diversity of picoeukaryotes in freshwater systems. In oligotrophic systems, picoeukaryotes are very important primary producers of biomass (Stenuite et al., 2009). Moreover, a high level of picoeukaryote diversity was recorded in mesotrophic lakes (Lepère et al., 2008; Lefèvre et al., 2008). Recent studies have reported that picophytoplankton is an important primary producer in eutrophic 
estuaries, contributing significantly to the total phytoplankton biomass (Murrell and Lores, 2004; Gaulke et al., 2010). In another study, researchers found that picophytoplankton abundance was quite high in rivers; it was almost equivalent to that in lakes and oceans (Contant and Pick, 2013). Currently, molecular techniques are used for surveying the diversity of picoeukaryotes that inhabit rivers (Thomasa et al., 2012), freshwater lakes (Zhao et al., 2011), and shallow aquatic environments (Simon et al., 2015a, b). However, we have little information about the diversity and distribution of picoeukaryotes, which thrive in an ecosystem of reservoir bay.

The Three Gorges Reservoir is located in the lower section of the upper reaches of Yangtze River in China (Han et al., 2015). The Xiangxi River is one of the longest rivers in the Three Gorges Reservoir region. After constructing the Three Gorges Dam, the Xiangxi River was transformed into Xiangxi Bay (Holbach et al., 2015). In this study, we used Sanger-based clone libraries of $18 \mathrm{~S}$ rRNA gene to determine the picoeukaryote diversity of three sampling sites, which were present along the Xiangxi Bay of the Three Gorges Reservoir; the picoeukaryote diversity was monitored across all the four seasons in 2013. We addressed the following basic questions: what is the picoeukaryotic diversity in the bay of a large reservoir? Does the mainstream reservoir affect the distribution pattern of picoeukaryote in the bay?

\section{Materials and methods}

\section{Sample collection and environmental data}

Water samples were collected from downstream (XX01, 3097'32.28’ N,

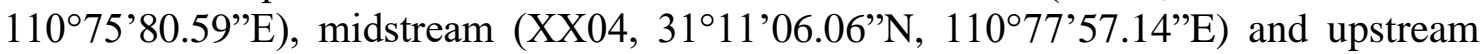
(XX07, 31 $\left.{ }^{\circ} 18^{\prime} 96.64^{\prime \prime N}, 110^{\circ} 75^{\prime} 33.75^{\prime} \mathrm{E}\right)$ of Xiangxi Bay of the Three Gorges Reservoir of China in February (winter), April (spring), August (summer), and October (autumn) of 2013 (Fig. 1). The linear distance between the XX01 and XX07 sample sites was approximately $26 \mathrm{~km}$.

Water samples were collected at a depth of $0.5 \mathrm{~m}$ beneath the water surface using a 5-L sampler and pre-filtered through $5 \mu \mathrm{m}$ pore-size polycarbonate filters (Millipore) followed by filtration onto $\mathrm{GF} / \mathrm{F}$ filters $(0.7 \mu \mathrm{m}$, Whatman) for molecular analyses. Samples were immediately frozen in liquid nitrogen and stored at $-80{ }^{\circ} \mathrm{C}$ until analysis.

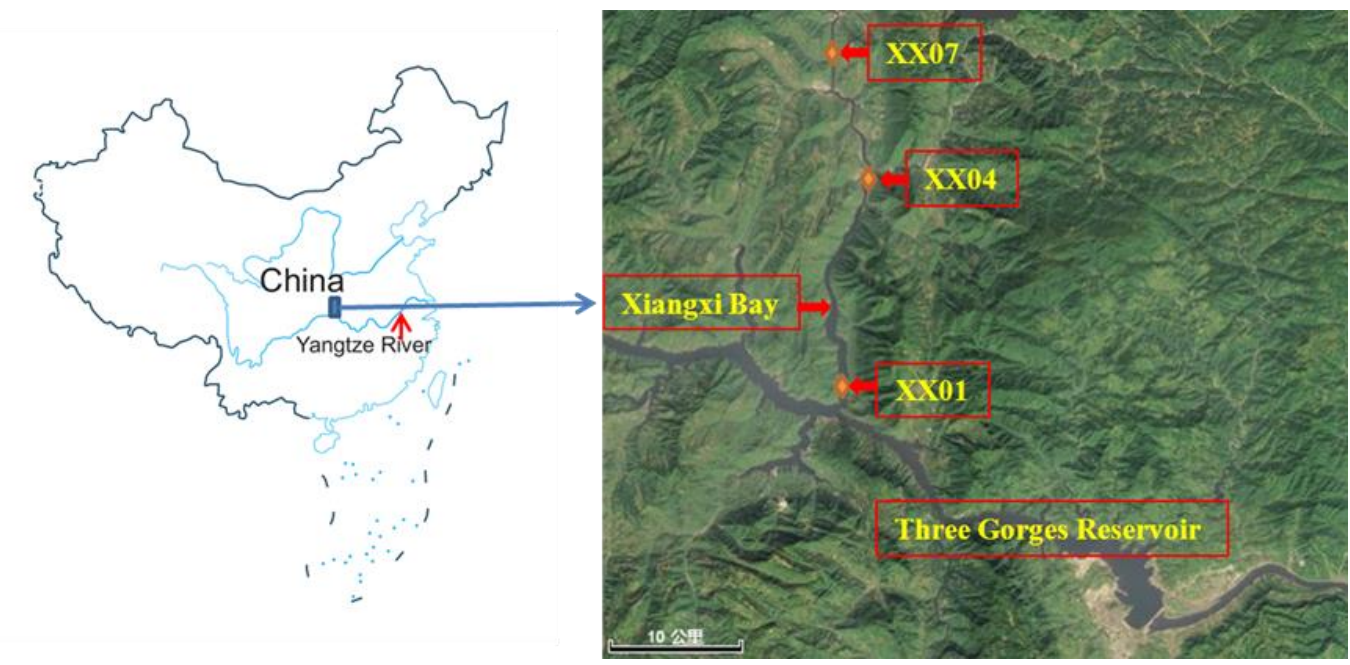

Figure 1. Map of study area and sampling site 
Physical and chemical factors, such as water temperature (WT), dissolved oxygen (DO), $\mathrm{pH}$ and turbidity, were measured in situ. Concentrations of total nitrogen (TN), orthophosphate $\left(\mathrm{P}_{-} \mathrm{PO}_{4}, \mathrm{PO} 43-\right)$, nitrate $\left(\mathrm{N}-\mathrm{NO}_{3}, \mathrm{NO} 3-\right)$, total phosphorus (TP), Chemical Oxygen Demand (COD), Oxidation-Reduction Potential (ORP), water transparency (SD) and ammonium (N-NH $4, \mathrm{NH} 4+$ ) were measured using standard methods, as described previously (Huang et al., 1999). The trophic states of the Xiangxi Bay in different sample sites and seasons were determined by comprehensive nutritional status index (trophic level index, TLI) using the values of TN, TP and SD (Tian et al., 2017). Trophic states are set as follows: TLI $\leq 30$, oligotrophic; $30<\mathrm{TLI} \leq 50$, mesotrophic; $50<\mathrm{TLI} \leq 60$, slightly eutrophic; $60<\mathrm{TLI} \leq 70$, moderately eutrophic; TLI $>70$, highly eutrophic (Meng and Zhao, 2007).

\section{DNA extraction and clone library construction}

DNA was extracted from filters using a previously described method (Countway et al., 2005). Near full-length $18 \mathrm{~S}$ rDNA fragments were amplified by polymerase chain reaction (PCR) using the eukaryotic-specific primers Euk328f/Euk329r (Euk328f: 5'-ACCTGGTTGATCCTGCCAG-3', Euk329r: 5'-TGATCCTTCYGCAGGTTCAC3') (Moon-van der Staay et al., 2000). PCR was carried out under the following conditions: 35 cycles (denaturation at $94{ }^{\circ} \mathrm{C}$ for $30 \mathrm{~s}$, annealing at $55^{\circ} \mathrm{C}$ for $45 \mathrm{~s}$, extension at $72{ }^{\circ} \mathrm{C}$ for $2 \mathrm{~min}$ ) proceeded by $3 \mathrm{~min}$ denaturation at $94{ }^{\circ} \mathrm{C}$ and followed by 8 min extension at $72{ }^{\circ} \mathrm{C} .18 \mathrm{~S}$ rDNA clone libraries were constructed using the pGEM $^{\circledR}$ $\mathrm{T}$ Easy Vector Systems (Promega) following the instructions provided by the manufacturer.

\section{Amplified ribosomal DNA restriction analysis (ARDRA)}

Positive clones from each library were screened by re-amplifying the $18 \mathrm{~S}$ rDNA by PCR as described above, except that $0.1 \mu \mathrm{l}$ of the culture of Escherichia coli containing the insert was used as a template. Positive PCR product was digested with HaeIII (Fermentas). Gel electronic images were visualized by means of ChemiDoc XRS (BioRad), images were analyzed with Image Lab software v. 3.0 (Bio-Rad). Clones with the same ARDRA pattern were grouped and considered as the same operational taxonomic unit (OTU).

\section{Statistical analyses}

Based on the result of ARDRA analysis, a library coverage value was computed according to the literature (Dang et al., 2008). Diversity indexes (Shannon and Pielou evenness) were also calculated. The Shannon diversity index is an index that is commonly used to characterize species diversity in a community. Pielou's evenness refers to how close in numbers each species in an environment are. The Kruskal-Wallis test was used for comparison between multiple groups. Bray-Curtis (temporal) dissimilarity based on relative abundance data OTUs was used as indices of the temporal turnover of community. The community structures were compared with nonmetric multidimensional scaling (NMDS) using Bray-Curtis distances. The significance of the observed differences was determined by permutational multivariate analysis of variance (PERMANOVA) based on Bray-Curtis distance measurements with 999 permutations. NMDS and. the Bray-Curtis dissimilarity between pairwise samples was 
calculated on the basis of OTU abundances. All these analyses were done using the R package vegan.

\section{Analysis based on sequence}

One or several representative clones of each ARDRA pattern were partially sequenced (Majorbio, China). Colonies were sequenced using the Euk 528F primer (5'GCGGTAATTCCAGCTCCAA-3') (Elwood et al., 1985). All sequences obtained were edited to exclude the primer sequence using Lasergene.v7.1 (DNAStar Inc), and checked for chimerical structures using the CHECK-CHIMERA program on the Ribosomal Database Project (http://rdp.cme.msu.edu/html/). In order to determine the phylogenetic affiliation, all non-chimeric sequences were aligned using the online automatic SILVA Incremental Aligner SINA v1.2.11 (http://www.arb-silva.de/aligner/) to identify known sequences with a high degree of similarity. Phyla that differed significantly $(q<0.05)$ for two groups were identified using White's non-parametric ttest with Storey's multiple testing correction in the STAMP software version 2.1 (Parks et al., 2014). Similarity percentage analysis (SIMPER) was used to assessing which taxa are primarily responsible for an observed difference between groups. SIMPER were carried out using PAST 3.18 (Hammer et al., 2001).

Correlations between picoeukaryotic communities and environmental factors were analyzed using the canonical correlation analysis (CCA) using R package vegan. CCA was performed using the relative abundance data of phyla (except rare phyla) and environmental factors. Significant environmental variables were chosen by the manual forward selection procedure, followed by Monte Carlo permutation tests (1000 iterations).

\section{Nucleotide sequence accession number}

The 18S rRNA gene sequences determined have been deposited in the GenBank database under accession numbers KX998709 - KX998893.

\section{Results}

\section{Environmental characterization}

The physicochemical parameters of water samples were present in Table Al in the Appendix. Among these parameters, statistically significant difference was observed in only TN values of the three sample sites ( $p=0.036$, Kruskal-Wallis tests). On the whole, the concentration of TN had increased gradually from upstream to downstream. Except for autumn, the TLI of the three sampling sites was greater than 50 through the year (Table A1, Fig. A1). The median TLI of three sampling sites (XX01, XX04, and XX07) was 51.57, 57.74, and 57.54, respectively (Fig. A1).

\section{S rDNA clone libraries}

In total, 12 clone libraries were constructed for the three sample sites. Approximately 85-105 clones were isolated from each clone library; these clones were then subjected to ARDRA analysis. In total, ARDRA analysis was performed on 1116 clones; these clones were clustered into 240 OTUs. In each sample, the number of OTUs ranged from 18 to 59. The coverage of respective libraries ranged from $63 \%$ to $91 \%$ (Table 1). The 
distribution of OTUs varied according to seasons or different sample sites. Only 31 OTUs appeared at all sites. Furthermore, only 6 OTUs appeared throughout the year (Fig. A2).

Table 1. Summary of ARDRA analysis of the 12 clone libraries

\begin{tabular}{c|c|c|c|c|c}
\hline Season & Sample sites & $\begin{array}{c}\text { No. of RFLP } \\
\text { types }\end{array}$ & Coverage & $\begin{array}{c}\text { Shannon- } \\
\text { Wiener }\end{array}$ & $\begin{array}{c}\text { Pielou } \\
\text { evenness }\end{array}$ \\
\hline \multirow{5}{*}{ Spring } & XX01 & 40 & $78.70 \%$ & 4.65 & 0.87 \\
& XX04 & 18 & $90.00 \%$ & 3.17 & 0.76 \\
& XX07 & 59 & $68.47 \%$ & 5.52 & 0.94 \\
\hline \multirow{3}{*}{ Summer } & XX01 & 36 & $68.42 \%$ & 4.64 & 0.89 \\
& XX04 & 44 & $71.27 \%$ & 4.94 & 0.90 \\
& XX07 & 35 & $72.50 \%$ & 4.47 & 0.86 \\
\hline \multirow{3}{*}{ Autumn } & XX01 & 29 & $90.76 \%$ & 3.54 & 0.71 \\
& XX04 & 48 & $68.13 \%$ & 5.29 & 0.85 \\
& XX07 & 55 & $63.16 \%$ & 5.51 & 0.95 \\
\hline \multirow{3}{*}{ Winter } & XX01 & 42 & $71.59 \%$ & 4.93 & 0.93 \\
& XX04 & 23 & $80.00 \%$ & 4.10 & 0.91 \\
& XX07 & 48 & $78.99 \%$ & 5.04 & 0.90 \\
\hline
\end{tabular}

The Shannon index and Pielou evenness index of 12 clone libraries were calculated (Table 1). The Shannon index peaked in upstream (XX07 site), and they were least in the middle reaches (XX04 site) of Xiangxi Bay (Fig. A1). No statistically significant difference was observed in the diversity index of the three sample sites; moreover, no statistically significant difference was observed for the four seasons of the year (all $p>0.09$, Kruskal-Wallis test).

\section{Picoeukaryotic community composition}

We obtained 185 high-quality sequences after removing all low-quality, unassembled, and potentially chimeric sequences. We performed phylogenetic analyses on 12 samples; the analyses results indicate that there were 13 phyla in these 12 samples (Fig. 2). Moreover, analyses results indicate that these libraries were dominated by Cryptophyta and Chlorophyta (32.4\% and $21.5 \%$ of the total 910 clones respectively), followed by Ciliophora (16\%) and Bacillariophyta (5.9\%), Chrysophyta (3.3\%). Telonemia, Pyrrhophyta, and Cercozoa were the three groups of picoeukaryotes, which were present in extremely low proportions. Besides, we also detected a very small amount of Haptophyta (1 sequence, 1 clone). Moreover, some kinds of fungi (Chytridiomycota, Cryptomycota, and Basidiomycota) and fungus-like (Oomycota) taxa were also detected in this study. The relative abundance of these fungi and fungus-like taxa was very low at the three sample sites. In these libraries, a significant number of sequences ( 37 sequences, $16.5 \%$ of the total 910 clones) were not affiliated with any formal taxa.

Among the Cryptophyta, an overwhelming majority belonged to Cryptomonadales (39 sequences); we also identified six sequences that were affiliated to uncultured Kathablepharidae. The Chlorophyta sequences were grouped into four taxa: 
Chlorophyceae, Chlorodendrophyceae, Mamiellophyceae, and Trebouxiophyceae. Among them, Chlorophycea was the most abundant taxon (26 of 35 Chlorophyta sequence). The Ciliophora sequences were grouped into three taxa: uncultured Choreotrichia, Litostomatea, and Prostomatea. Among them, uncultured Choreotrichia was the most abundant taxon (20 of 40 Ciliophora sequence). All the six sequences of Bacillariophyta belonged to the taxon Mediophyceae. Chrysophyta contained different types of sequences: three sequences were affiliated to the taxon Chrysophyceae, while one sequence was affiliated to Nannochloropsis. Telonemia consisted of four sequences, which were affiliated to the taxon Telonema (Shalchian-Tabrizi et al., 2006).

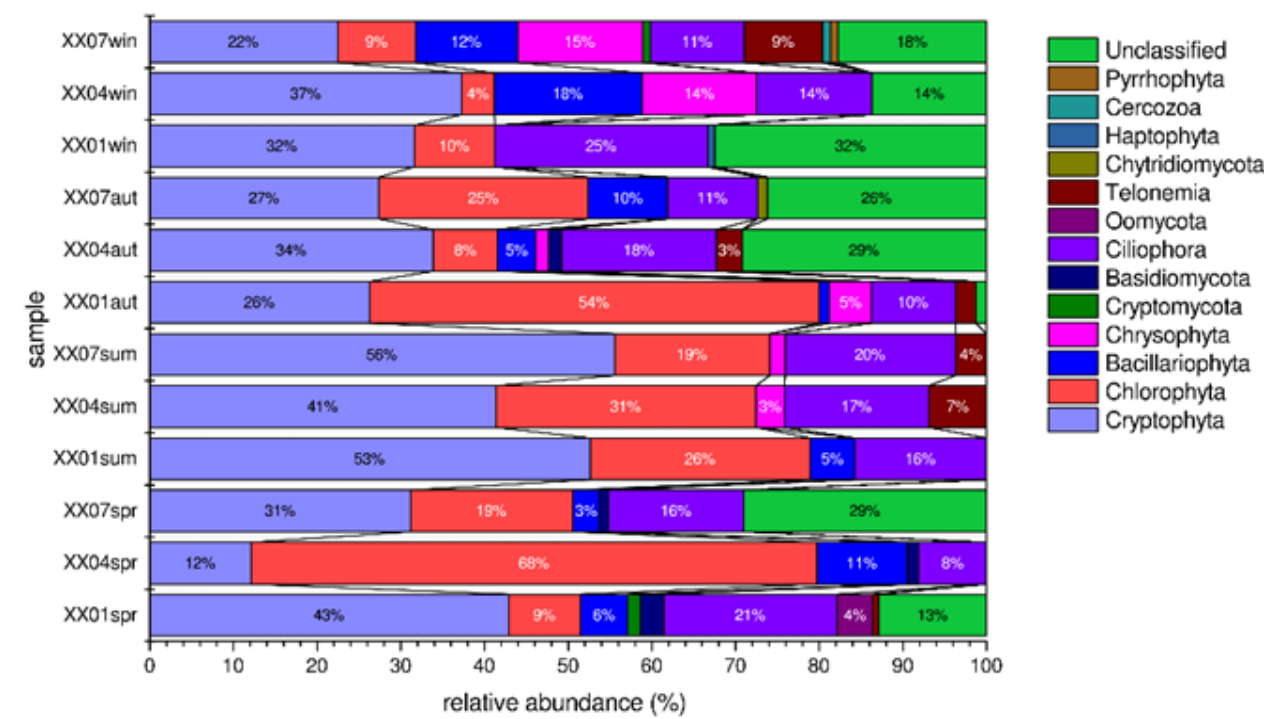

Figure 2. Distribution of the phyla in all samples. Spr: spring, sum: summer, aut: autumn, win: winter

\section{Community structure across space and time}

From winter to spring, the structure of picoeukaryotic communities changed slightly; a different picoeukaryotic community structure was observed from summer to autumn, with slight variation in composition. Seasonal patterns were detected by NMDS analyses (Fig. 3). By performing PERMANOVA analyses, we found that the composition of picoeukaryotic communities was significantly different across all the four seasons $(p=0.0011)$; however, there was no significant difference between the composition of picoeukaryotic communities of three sample sites $(p=0.9937)$. By SIMPER analysis, we observed the seasonal differences were mainly attributed to appreciable seasonal fluctuations in the relative abundance of dominant phyla. The seasonal differences were mainly observed in following phyla: Chlorophyta $(24.41 \%)$, Cryptophyta (20.3\%), and Ciliophora (12.25\%).

In Xiangxi Bay, picoeukaryotes were unevenly distributed across the three sample sites; moreover, the distribution of picoeukaryotes also changed across the four seasons. By determining the Bray-Curtis dissimilarity matrix of all the samples, we found that the community temporal stability decreased from upstream to downstream (Fig. 4). By STAMP analysis, we found that Basidiomycota has a significantly higher abundance in spring than in summer $(q<0.01)$ (Fig. 5). No significant variations were observed in the composition of the phyla, regardless of the sample site. 


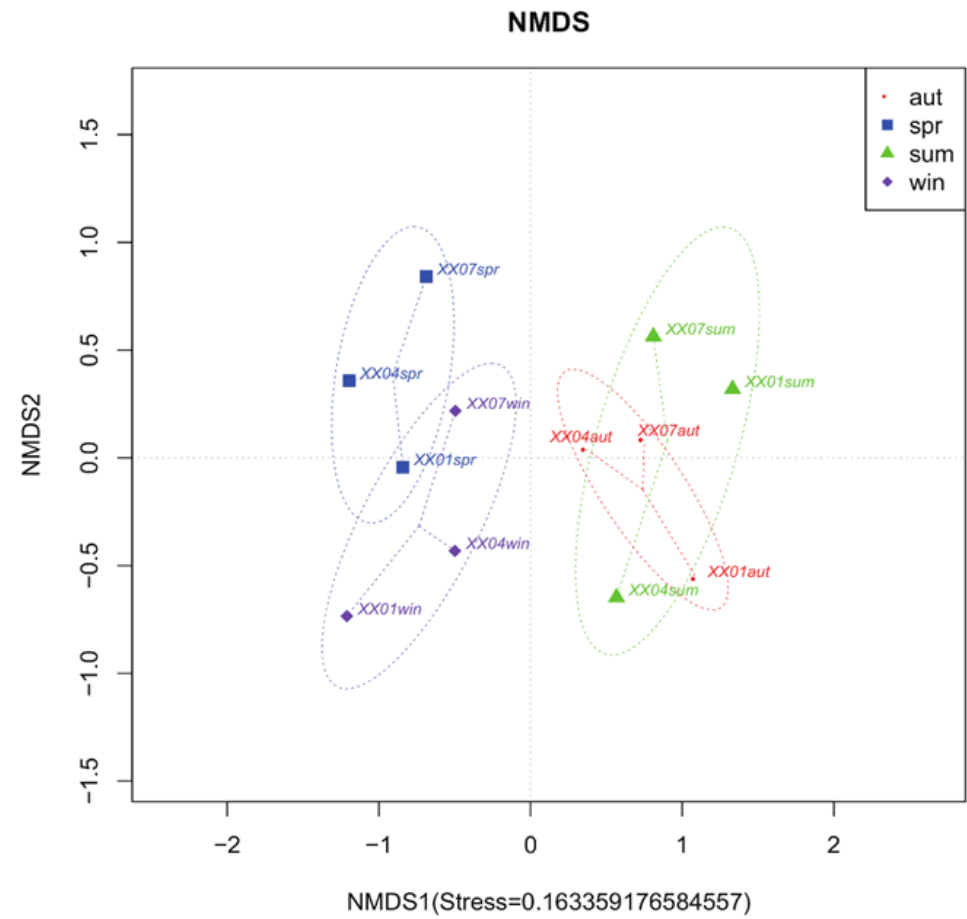

Figure 3. Non-metric MultiDimensional Scaling (NMDS) plot based on Bray-Curtis distances

\section{Picoeukaryotic communities in relation to environmental variables}

The results of CCA analysis indicate that abundances of specific taxa depended upon environmental variables (Fig. 6). The first two axes accounted for $35.3 \%$ of the variance. The abundances of Chrysophyta and Bacillariophyta were negatively related to $\mathrm{pH}$ and turbidity. The distribution of Bacillariophyta was greater in the area with higher concentration of $\mathrm{N}-\mathrm{NH}_{4}$. The distribution of Chrysophyta was concentrated in the least turbid area, which had lower values of $\mathrm{N}-\mathrm{NH}_{4}$.

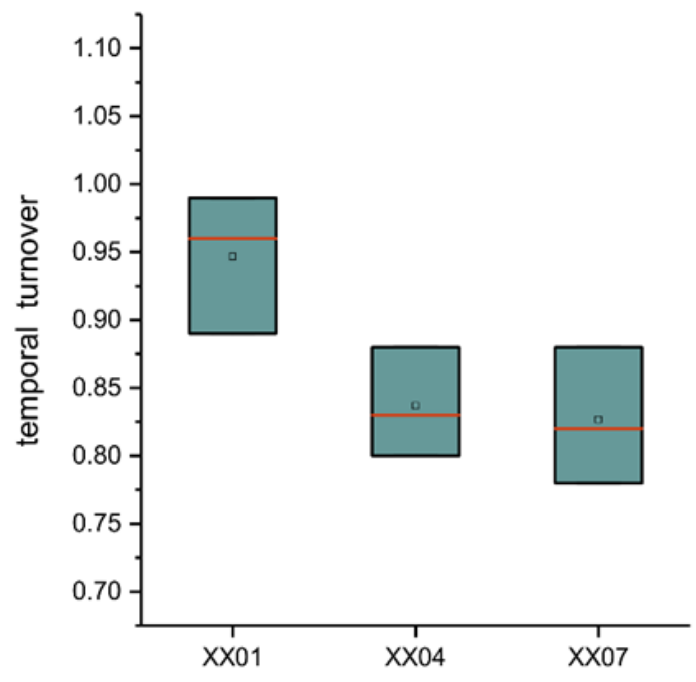

Figure 4. Boxplot of spring-summer, summer-autumn and autumn-winter pairwise dissimilarity (temporal turnover) coefficient of the three sample sites. Median is indicated by the red center lines, arithmetic average is indicated by the black hollow circle 


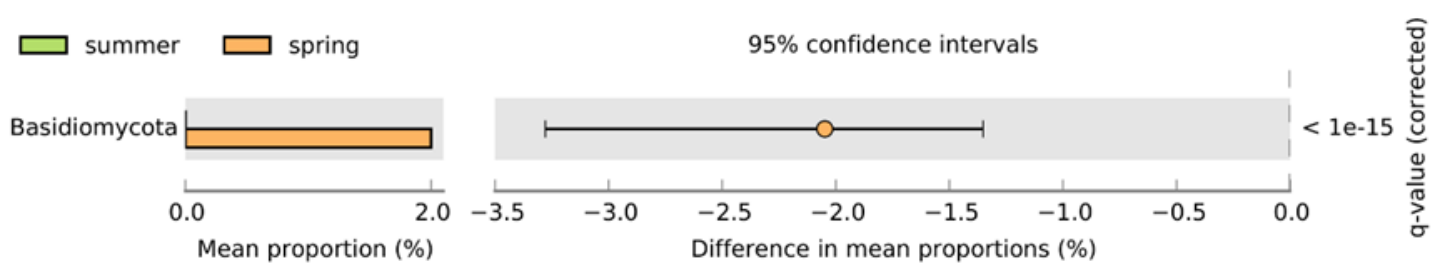

Figure 5. Phyla that was significantly different between two seasons

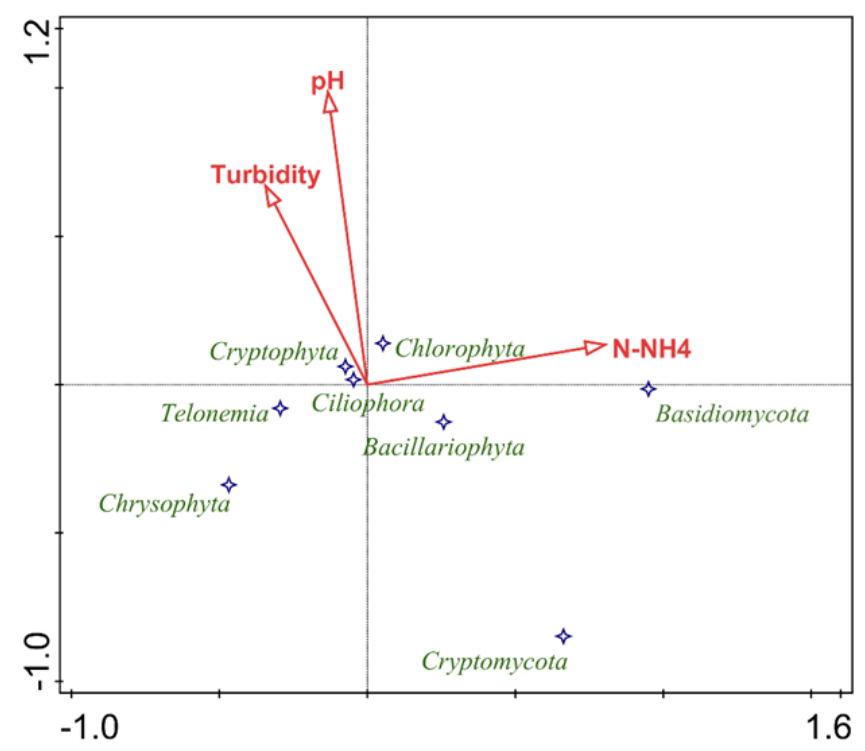

Figure 6. Canonical correspondence analysis (CCA) plot for the environmental parameters and the picoeukaryotic communities. N-NH4: ammonium

\section{Discussion}

In this study, we found that TLI was the highest in middle reaches (XX04 site) and least in the downstream (XX01 site) of Xiangxi Bay (Fig. Al). There is water exchange between the Three Gorges Reservoir mainstream and its tributaries (Liu et al., 2012; Huang et al., 2014). Owing to water exchange, nutrients are supplied from the Three Gorges Reservoir mainstream to the Xiangxi Bay (Yang et al., 2015). Water exchange occurs frequently at the river mouth; however, the time of water retention is short (Liu et al., 2012). Consequently, the middle reaches of Xiangxi Bay were replenished with several nutrients (Ji et al., 2010). Therefore, middle reaches of Xiangxi Bay have the highest TLI.

Previous studies have reported that the diversity of species decreases with eutrophication (Baho et al., 2017; Cook et al., 2018). Therefore, the diversity index was lowest in middle reaches of Xiangxi Bay (Fig. Al). Surprisingly, the diversity index was highest at the upstream (XX07 site) of Xiangxi Bay, but its trophic level was higher than the downstream of Xiangxi Bay. With the flows of water, soil, litter, and anthropogenic materials were transported in and around rivers. These materials got easily mixed with the resident microbial communities (Mansour et al., 2018). Recently, several studies have been carried out on different water ecosystems; these studies have reported that terrestrial microbes show significant abundance in the microbial communities of headwater ecosystems (Crump et al., 2012; Besemer et al., 2013; Ruiz- 
González et al., 2015). In the upstream sampling site, microbial diversity could be structured by inoculating the microbes from terrestrial sources; these microbes would contribute to community assembly. This may be the reason for the differences in the diversity of picoeukaryotic communities, which are found in the down and upper reaches of Xiangxi Bay.

The upstream of Xiangxi Bay had the highest diversity index, while the midstream of Xiangxi Bay had the lowest diversity index (Fig. Al). Before the construction of the Three Gorges Reservoir, the diversity index of Xiangxi River was lower down-stream (Kuang et al., 2004). This implies that the distribution pattern of plankton diversity has changed to some extent after the construction of the Three Gorges Reservoir. Furthermore, our results indicate that diversity indices of summer and winter were greater than those of spring and autumn (Fig. A3). Similar results have been presented by researchers in previous studies (Zhang et al., 2017). Previous studies have proved that the mainstream of Three Gorges Reservoir significantly influences its tributaries in spring and autumn seasons: this is because water is discharged from the mainstream of Three Gorges Reservoir during spring season; moreover, water is impounded into the same reservoir during autumn (Li et al., 2012). After analyzing the diversity indices and temporal turnover of picoeukaryotic communities, we infered that the Three Gorges Reservoir does impact plankton diversity of its tributaries.

The concentration of $\mathrm{N}-\mathrm{NO}_{3}$ is much higher than that of $\mathrm{N}-\mathrm{NH}_{4}$ in Xiangxi Bay (Table A1). The results of ordination analysis prove that Bacillariophyta had a positive relationship with $\mathrm{N}-\mathrm{NH}_{4}$. In the presence of sufficient nutrients, diatoms are generally $\mathrm{N}-\mathrm{NO}_{3}$ opportunists (Donald et al., 2011; Glibert and Wilkerson, 2014). Some studies have reported that diatoms are distributed in the area, which has higher concentration of $\mathrm{N}-\mathrm{NH}_{4}$ values (Zhao et al., 2013). Therefore, further studies must be conducted to determine whether elevated levels of $\mathrm{N}-\mathrm{NH}_{4}$ favor the growth of pico-diatoms in Xiangxi Bay. Chrysophyta often grows in highly transparency water, which has low organic content (Lin et al., 2003). In this survey, Chrysophyta appear in less turbid areas, which have comparatively lower concentration of $\mathrm{N}-\mathrm{NH}_{4}$. The relative abundance of Chrysophyta was much greater in oligotrophic lakes than in Xiangxi Bay. This indicates that eutrophication affects the composition of plankton communities in different water bodies.

In summary, water exchange between Xiangxi Bay and Three Gorges Reservoir mainstream may affected the distribution pattern of biodiversity and nutritional state of Xiangxi Bay. So, middle reaches of Xiangxi Bay have the highest TLI. Furthermore, upper reaches exhibited highest species diversity, whereas middle reaches exhibited lowest species diversity. In Xiangxi Bay, the seasonal variability of communities overwhelms spatial patterns. The community temporal stability had decreased from upstream to downstream. In the upstream sampling site, microbial diversity could be structured by inoculating the microbes from terrestrial sources.

Acknowledgements. This research was supported by the National Natural Science Foundation of China (41171045) and the Research Fund for Science and Technology Inovation Team of University (T201504). 


\section{REFERENCES}

[1] Baho, D. L., Drakare, S., Johnson, R. K., Allen, C. R., Angeler, D. G. (2017): Is the impact of eutrophication on phytoplankton diversity dependent on lake volume/ecosystem size? - Journal of Limnology 76: 199-210.

[2] Besemer, K., Singer, G., Quince, C., Bertuzzo, E., Sloan, W., Battin, T. J. (2013): Headwaters are critical reservoirs of microbial diversity for fluvial networks. Proceedings of the Royal Society B: Biological Sciences 280: 20131760.

[3] Biegala, I. C., Not, F., Vaulot, D., Simon, N. (2003): Quantitative assessment of picoeukaryotes in the natural environment by using taxon-specific oligonucleotide probes in association with tyramide signal amplification-fluorescence in situ hybridization and flow cytometry. - Applied and Environmental Microbiology 6: 5519-5529.

[4] Caron, D., Countway, P., Jones, A., Kim, D., Schnetzer, A. (2012): Marine protistan diversity. - Annual Review of Marine Science 4: 467-493.

[5] Contant, J., Pick, F. R. (2013): Picophytoplankton during the ice-free season in five temperate-zone rivers. - Journal of Plankton Research 35: 553-565.

[6] Cook, S. C., Housley, L., Back, J. A., King, R. S. (2018): Freshwater eutrophication drives sharp reductions in temporal beta diversity. - Ecology 99: 47-56.

[7] Countway, P. D., Gast, R. J., Savai, P., Caron, D. A. (2005): Protistan diversity estimates based on 18S rDNA from seawater incubations in the Western North Atlantic. - Journal of Eukaryotic Microbiology 52: 95-106.

[8] Crump, B. C., Amaral-Zettler, L. A., Kling, G. W. (2012): Microbial diversity in arctic freshwaters is structured by inoculation of microbes from soils. - The ISME Journal 6: 1629-1639.

[9] Dang, H. Y., Li, T. G., Chen, M. G., Huang, G. Q. (2008): Cross-ocean distribution of rhodobacterales bacteria as primary surface colonizers in temperate coastal marine waters. - Applied and Environmental Microbiology 74: 52-60.

[10] Donald, D. B., Bogard, M. J., Finlay, K., Leavitt, P. R. (2011): Comparative effects of urea, ammonium, and nitrate on phytoplankton abundance, community composition, and toxicity in hypereutrophic freshwaters. - Limnology and Oceanography 56: 2161-2175.

[11] Elwood, H. J., Olsen, G. J., Sogin, M. L. (1985): The small-subunit ribosomal RNA gene sequences from the Hypotrichou Ciliates Oxytricha nova and Stylonychia pustulata. Molecular Biology and Evolution 2: 399-410.

[12] Farnelid, H. M., Turk-Kubo, K. A., Zehr, J. P. (2016): Identification of associations between bacterioplankton and photosynthetic picoeukaryotes in coastal waters. Frontiers in Microbiology 7: 339.

[13] Gaulke, A. K., Wet, M. S., Paerl, H. W. (2010): Picophytoplankton: a major contributor to planktonic biomass and primary production in a eutrophic, river-dominated estuary. Estuarine, Coastal and Shelf Science 90: 45-54.

[14] Glibert, P. M., Wilkerson, F. P. (2014): Phytoplankton communities from San Francisco Bay Delta respond differently to oxidized and reduced nitrogen substrates even under conditions that would otherwise suggest nitrogen sufficiency. - Frontiers in Marine Science 1: 1-16.

[15] Hammer, Ø., Harper, D. A. T., Ryan, P. D. (2001): PAST: Paleontological statistics software package for education and data analysis. - Palaeontologia Electronica 4: 9.

[16] Han, L. F., Gao, B., Zhou, H. D., Xu, D. Y., Wei, X., Gao, L. (2015): The spatial distribution, accumulation and potential source of seldom monitored trace elements in sediments of Three Gorges Reservoir, China. - Scientific Reports 5: 16170.

[17] Holbach, A., Bi, Y., Yuan, Y., Wang, L., Zheng, B., Norra, S. (2015): Environmental water body characteristics in a major tributary backwater of the unique and strongly seasonal Three Gorges Reservoir, China. - Environmental Science: Processes \& Impacts 17: 1641-53. 
[18] Huang, X. F., Chen, W. M., Cai, Q. M. (1999): Survey, observation and analysis of lake ecology. - China Standard Press, Beijing, pp. 45-79 (in Chinese).

[19] Huang, Y. L., Zhang, P., Liu, D. F., Yang, Z. J., Ji, D. B. (2014): Nutrient spatial pattern of the upstream, mainstream and tributaries of the Three Gorges Reservoir in China. Environmental Monitoring and Assessment 186: 6833-6847.

[20] Ji, X. P., Liu, D. F., Huang, Y. L., Ji, D. B., Yi, Z. Q. (2010): Dynamic characteristics of nutrients in Xiangxi Bay and converse impact from mainstream in drainage period of the Three Gorges Reservoir. - Chinese Journal of Environmental Engineering 4: 2687-2693 (in Chinese).

[21] Kuang, Q. J., Hu, Z. Y., Zhou, G. J., Ye, L., Cai, Q. H. (2004): Investigation on phytoplankton in Xiangxi River Watershed and the evaluation of its water quality. - Plant Science Journal 22: 507-513 (in Chinese).

[22] Lefèvre, E., Roussel, B., Amblard, C., Sime-Ngando, T. (2008): The molecular diversity of freshwater picoeukaryotes reveals high occurrence of putative parasitoids in the plankton. - PLOS ONE 3: e2324.

[23] Lepère, C., Domaizon, I., Debroas, D. (2008): Unexpected importance of potential parasites in the composition of the freshwater small-eukaryote community. - Applied and Environmental Microbiology 74: 2940-2949.

[24] Li, W. K. W. (1994): Primary production of prochlorophytes, cyanobacteria, and eucaryotic ultraphytoplankton: measurements from flow cytometric sorting. - Limnology and Oceanography 39: 169-175.

[25] Li, Y., Liu, D. F., Kong, S., Ji, D. B., Yang, Z. J., Chen, Y. Y. (2012): Comparative analysis of the impact of discharging and impounding process of Three Gorges Reservoir on the algal bloom in the Xiangxi Bay. - Acta Scientiae Circumstantiae 32: 1882-1893 (in Chinese).

[26] Lin, Q. Q., Hu, R., Duan, S. S., Han, B. P. (2003): Reservoir trophic states and the response of plankton in Guangdong Province. - Acta Ecologica Sinica 23: 1101-1108 (in Chinese).

[27] Liu, L., Liu, D. F., Johnson, D. M., Yi, Z. Q., Huang, Y. L. (2012): Effects of vertical mixing on phytoplankton blooms in Xiangxi Bay of Three Gorges Reservoir: Implications for management. - Water Research 46: 2121-2130.

[28] Mansour, I., Heppell, C. M., Ryo, M., Rillig, M. C. (2018): Application of the microbial community coalescence concept to riverine networks. - Biological Reviews https://doi.org/10.1111/brv.12422.

[29] Massana, R., Pernice, M., Bunge, J. A., Campo, J. D. (2011): Sequence diversity and novelty of natural assemblages of picoeukaryotes from the Indian Ocean. - The ISME Journal 5: 184-195.

[30] Meng, C. H., Zhao, B. (2007): Study on the trend of eutrophication after impounding in Three Gorges Reservoir. - Journal of Agro-Environment Science 26: 863-867.

[31] Moon-van der Staay, S. Y., van der Staay, G. W. M., Guillou, L., Vaulot, D., Claustre, H., Medlin, L. K. (2000): Abundance and diversity of prymnesiophytes in the picoplankton community from the equatorial Pacific Ocean inferred from 18S rDNA sequences. - Limnology and Oceanography 45: 98-109.

[32] Murrel, M. C., Lores, E. M. (2004): Phytoplankton and zooplankton seasonal dynamics in a subtropical estuary: importance of cyanobacteria. - Journal of Plankton Research 26: 371-382.

[33] Parks, D., Tyson, G. W., Hugenholtz, P., Beiko, R. G. (2014): STAMP: statistical analysis of taxonomic and functional profiles. - Bioinformatic 30: 3123-3124.

[34] Ruiz-González, C., Niño-García, J. P., del Giorgio, P. A. (2015): Terrestrial origin of bacterial communities in complex boreal freshwater networks. - Ecology Letters 18: 1198-1206.

[35] Shalchian-Tabrizi, K., Eikrem, W., Klaveness, D., Vaulot, D., Minge, M., Le Gall, F., Romari, K., Throndsen, J., Botnen, A., Massana, R., Thomsen, H., Jakobsen, K. (2006): 
Telonemia, a new protist phylum with affinity to chromist lineages. - Proceedings of the Royal Society B: Biological Sciences 273: 1833-1842.

[36] Simon, M., Jardillier, L., Deschamps, P., Moreira, D., Restoux, G., Bertolino, P., LópezGarcía, P. (2015a): Complex communities of small protists and unexpected occurrence of typical marine lineages in shallow freshwater systems. - Environmental Microbiology 17: 3610-3627.

[37] Simon, M., López-García, P., Deschamps, P., Moreira, D., Restoux, G., Bertolino, P., Jardillier, L. (2015b): Marked seasonality and high spatial variability of protist communities in shallow freshwater systems. - The ISME Journal 9: 1943-1951.

[38] Stenuite, S., Tarbe, A. L., Sarmento, H., Unrein, F., Pirlot, S., Sinyinza, D., Thill, S., Lecomte, M., Leporcq, B., Gasol, J. M., Descy, J. P. (2009): Photosynthetic picoplankton in Lake Tanganyika: biomass distribution patterns with depth, season and basin. - Journal of Plankton Research 31: 1531-1544.

[39] Thomasa, M. C., Selingerb, L. B., Inglisa, G. D. (2012): Seasonal diversity of planktonic protists in Southwestern Alberta Rivers over a 1-year period as revealed by terminal restriction fragment length polymorphism and 18S rRNA gene library analyses. Applied and Environmental Microbiology 78: 5653-5660.

[40] Tian, W., Zhang, H. Y., Zhao, L., Zhang, F. F., Huang, H. (2017): Phytoplankton diversity effects on community biomass and stability along nutrient gradients in a eutrophic lake. - International Journal of Environmental Research and Public Health 14: 95.

[41] Vaulot, D., Eikrem, W., Viprey, M., Moreau, H. (2008): The diversity of small eukaryotic phytoplankton $(<3 \mu \mathrm{m})$ in marine ecosystems. - FEMS Microbiology Ecology 32: 95-820.

[42] Wu, W. X., Huang, B. Q., Zhong, C. (2014): Photosynthetic picoeukaryote assemblages in the South China Sea from the Pearl River estuary to the SEATS station. - Aquatic Microbial Ecology 71: 271-284.

[43] Yang, L., Liu, D. F., Huang, Y. L., Yang, Z. J., Ji, D. B., Song, L. X. (2015): Isotope analysis of the nutrient supply in Xiangxi Bay of the Three Gorges Reservoir. Ecological Engineering 77: 65-73.

[44] Zhang, J. L., Zheng, B. H., Liu, D. F., Wang, L. J., Tan, Q. R. (2017): Succession pattern of phytoplankton of Daning River in the Three Gorges Reservoir and its driving factors. Environmental Science 38: 535-546 (in Chinese).

[45] Zhao, B. Y., Chen, M. J., Sun, Y., Yang, J. X., Chen, F. Z. (2011): Genetic diversity of picoeukaryotes in eight lakes differing in trophic status. - Canadian Journal of Microbiology 57: 115-126.

[46] Zhao, Z., Mi, T., Xia, L., Yan, W. M., Jiang, Y., Gao, Y. Z. (2013): Understanding the patterns and mechanisms of urban water ecosystem degradation: phytoplankton community structure and water quality in the Qinhuai River, Nanjing City, China. Environmental Science and Pollution Research 20: 5003-5012. 


\section{APPENDIX}

Table A1. Physical and environmental characteristics of the sampling stations. Spr: spring, sum: summer, aut: autumn, win: winter. WT: water temperature, DO: dissolved oxygen, TN: total nitrogen, P-PO4: orthophosphate, N-NO3: nitrate, TP: total phosphorus, N-NH4: ammonium, COD: chemical oxygen demand, ORP: oxidation-reduction potential, TLI: trophic level index

\begin{tabular}{|c|c|c|c|c|c|c|c|c|c|c|c|c|}
\hline & XX01spr & XX04spr & XX07spr & XX01sum & XX04sum & XX07sum & XX01aut & XX04aut & XX07aut & XX01win & XX04win & XX07win \\
\hline $\mathbf{T P}(\mathrm{mg} / \mathrm{L})$ & 0.20 & 0.24 & 0.41 & 0.08 & 0.15 & 0.26 & 0.07 & 0.08 & 0.05 & 0.15 & 0.17 & 0.20 \\
\hline $\mathrm{P}_{-} \mathrm{PO}_{4}(\mathrm{mg} / \mathrm{L})$ & 0.16 & 0.14 & 0.27 & 0.10 & 0.01 & 0.05 & 0.07 & 0.06 & 0.04 & 0.13 & 0.17 & 0.19 \\
\hline $\mathrm{N}-\mathrm{NH}_{4}(\mathrm{mg} / \mathrm{L})$ & 0.12 & 0.14 & 0.04 & 0.02 & 0.05 & 0.07 & 0.03 & 0.03 & 0.03 & 0 & 0 & 0.02 \\
\hline $\mathrm{N}-\mathrm{NO}_{3}(\mathrm{mg} / \mathrm{L})$ & 1.54 & 0.80 & 0.11 & 1.00 & 0.84 & 0.12 & 1.47 & 1.22 & 1.11 & 1.73 & 1.39 & 1.33 \\
\hline $\mathrm{TN}(\mathrm{mg} / \mathrm{L})$ & 1.77 & 1.24 & 0.91 & 1.6 & 2.17 & 1.34 & 1.55 & 1.47 & 1.19 & 1.84 & 1.47 & 1.45 \\
\hline $\operatorname{COD}(\mathrm{mg} / \mathrm{L})$ & 1.13 & 1.94 & 3.76 & 2.59 & 3.76 & 3.69 & 1.86 & 1.86 & 2.18 & 1.2 & 1.24 & 1.28 \\
\hline WT $\left({ }^{\circ} \mathbf{C}\right)$ & 17.40 & 18.70 & 21.10 & 29.60 & 28.70 & 29.50 & 24.50 & 24 & 24.10 & 12.80 & 12.20 & 12.4 \\
\hline $\mathrm{DO}(\mathrm{mg} / \mathrm{L})$ & 7.96 & 12.3 & 18 & 12.5 & 8.16 & 15.6 & 7.7 & 7.3 & 7.81 & 9.18 & 9.74 & 9.01 \\
\hline ORP(mV) & 255 & 211.7 & 192.1 & 61.2 & 61.6 & 48.1 & 104.6 & 95.2 & 88.7 & 304.1 & 295.7 & 298 \\
\hline pH & 8.24 & 8.83 & 9.43 & 9.31 & 9.08 & 9.75 & 8.68 & 8.81 & 8.85 & 8.19 & 8.34 & 8.28 \\
\hline Turbidity(NTU) & 1.30 & 5.80 & 6.10 & 8.20 & 18 & 17.80 & 1.40 & 2.40 & 2.10 & 1.20 & 1.10 & 1.20 \\
\hline TLI & 50.71 & 60.97 & 62.25 & 54.41 & 61.44 & 64.46 & 49.58 & 51.7 & 48.95 & 52.44 & 54.52 & 52.83 \\
\hline
\end{tabular}
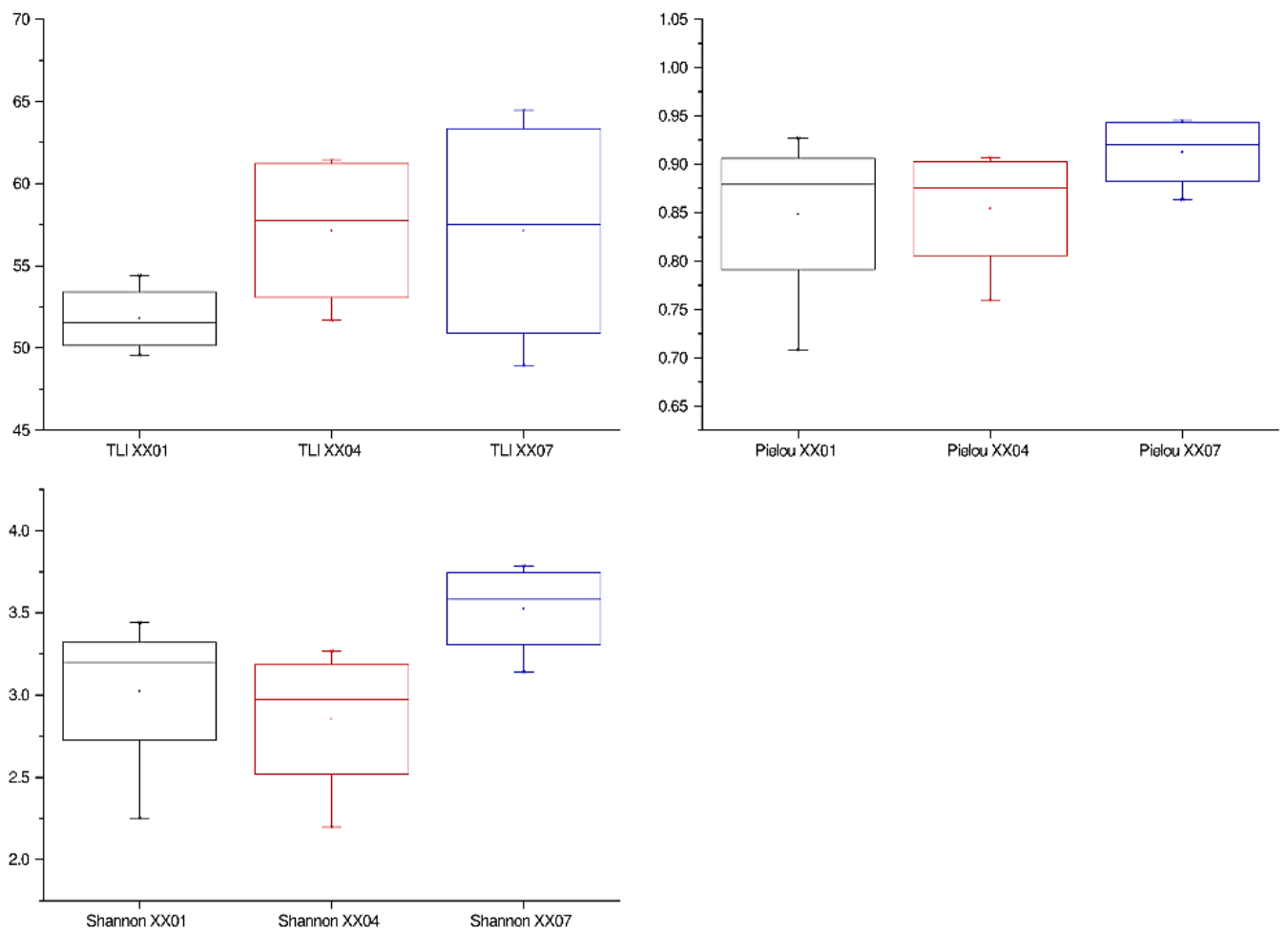

Figure A1. Nutritional status and diversity index plot. TLI: trophic level index. Median is indicated by the center lines, arithmetic average is indicated by the hollow circle 

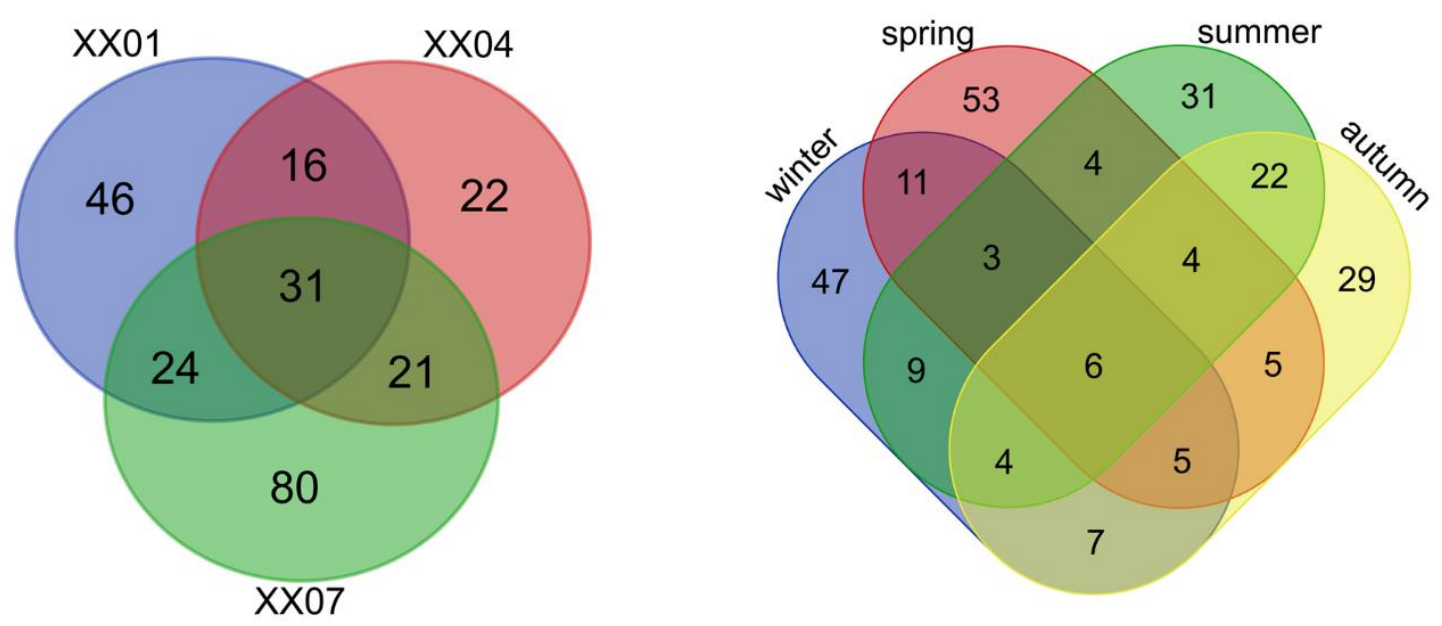

Figure A2. Venn diagrams showing shared and unique season and sample sites OTUs based on clone libraries
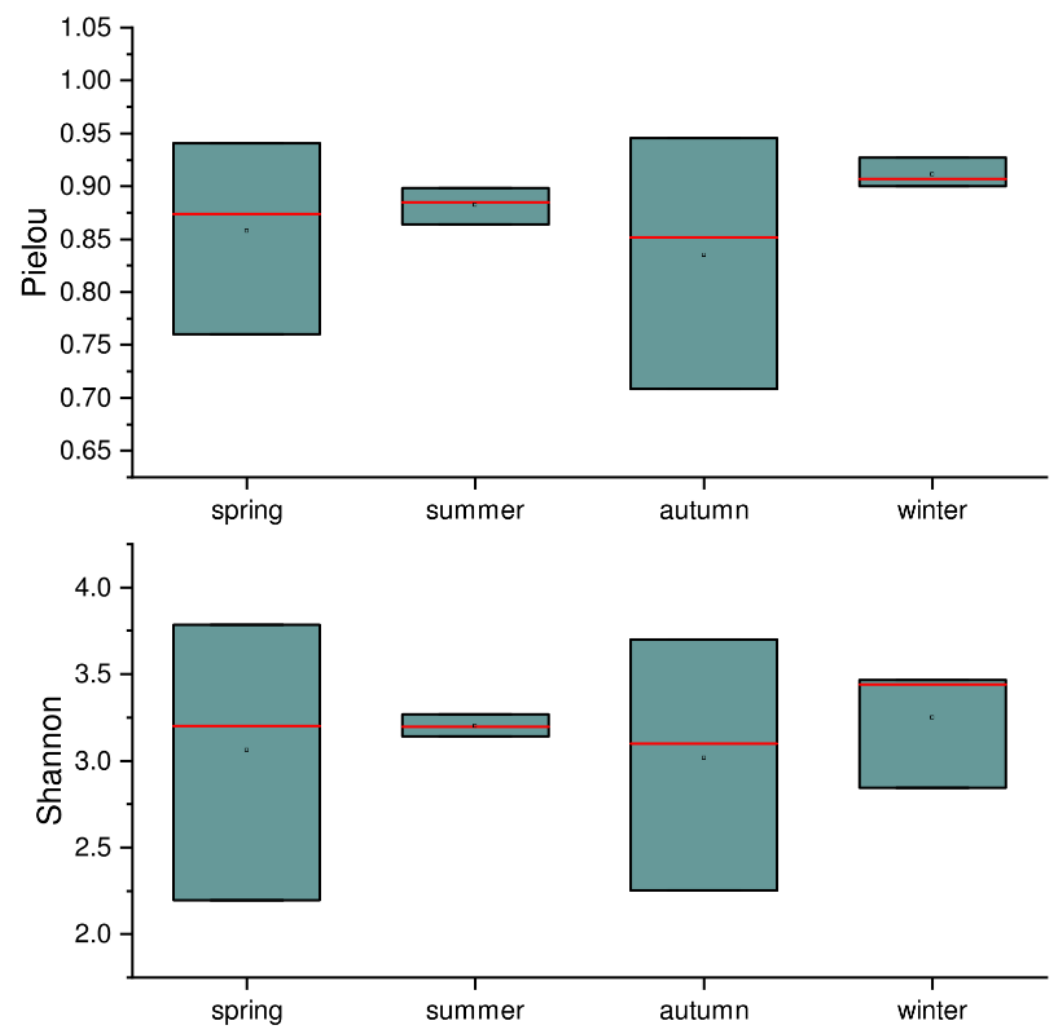

Figure A3. Boxplot of the Shannon and Pielou evenness indexes among the four seasons. Median is indicated by the red center lines, arithmetic average is indicated by the black hollow circle 